\title{
Retroperitoneal Castleman's disease: advocating a multidisciplinary approach for a rare clinical entity
}

\author{
Austin D Williams', Adriana Sanchez ${ }^{2}$, Jun Steve Hou², Rene Rothstein Rubin ${ }^{3}$, Mark E Hysell ${ }^{4}$, Blake D Babcock', \\ Mohammad F Shaikh', Michael S Weingarten ${ }^{5}$ and Wilbur B Bowne ${ }^{1 *}$
}

\begin{abstract}
Background: Castleman's disease is a rare and poorly understood disease entity that may resemble more common conditions and represents a clinical challenge to the treating surgeon.

Case presentation: In this report, we describe a case of a 61-year-old Caucasian woman with a symptomatic retroperitoneal mass. The specimen obtained from her resection contained a protuberant encapsulated mass, exhibiting microscopic features consistent with localized, unicentric Castleman's disease. These characteristics included architectural features and immunohistochemical findings consistent with the hyaline vascular variant of Castleman's disease.

Conclusion: We report a very rare case of a retroperitoneal hyaline vascular type of Castleman's disease. We discuss the diagnostic dilemma Castleman's disease may present to the surgeon, with an emphasis on multidisciplinary management of these patients. We also review current data on pathogenesis, treatment and outcomes.
\end{abstract}

Keywords: Angiofollicular lymph node hyperplasia, Castleman's disease, Management, Multidisciplinary care

\section{Background}

Angiofollicular lymph node hyperplasia, or Castleman's disease $(\mathrm{CD})$, is a rare neoplastic disease first identified in 1956 by Castleman and colleagues [1]. It has been described mainly in case reports and small series, thus the incidence and prevalence of $\mathrm{CD}$ are difficult to ascertain. $\mathrm{CD}$ is characterized by massive growth of nonclonal lymphoid tissue and has been categorized according to anatomic location, histological presentation and centricity (local vs. multicentric). In $65 \%$ to $80 \%$ of cases, CD is primarily found in the mediastinum, with an increasing incidence noted in the head and neck region. Mesenteric, retroperitoneal and pelvic tumors are unique and discovered less frequently [2-4]. Clinical imaging cannot readily distinguish $\mathrm{CD}$ from other neoplastic diseases. Published reports have described CD mimicking lymphoma, carcinoma and sarcoma in various anatomic sites, such as the pancreas, liver and spinal cord [5-7].

The classic histological subtype of $\mathrm{CD}$, representing $76 \%$ to $91 \%$ of localized disease, is the hyaline-vascular

\footnotetext{
* Correspondence: wilbur.bowne@drexelmed.edu

'Division of Surgical Oncology, Department of Surgery, Drexel University College of Medicine, 254 N. 15th St., MS 413, Philadelphia, PA 19102, USA Full list of author information is available at the end of the article
}

type (HV-CD). The plasma cell variant (PC-CD) has been identified in $9 \%$ to $24 \%$ of $C D$ cases, and a rare hyalinevascular plasma cell (or mixed) subtype has also been reported $[2,8,9]$. Clinically, HV-CD is most often found in indolent unicentric CD tumors (UCDs), and a more generalized (multicentric) lymphadenopathy, which frequently presents with constitutional symptoms, is associated with PC-CD $[2,10]$.

$\mathrm{CD}$ has an unclear etiology, although human herpes virus 8 (HHV-8) and HIV coinfection has been implicated in the etiology of multicentric disease (MCD). Although it has been hypothesized that treatment with highly active antiretroviral therapies might decrease the incidence of MCD, MCD has actually increased and further study elucidating the effects of viral seropositivity on dysregulation of the immune system is ongoing [11]. Additionally, the roles of autoimmune diseases and Epstein-Barr virus (EBV) infection in the pathogenesis of $\mathrm{CD}$ are now being explored [12,13].

Historically, the treatment and prognosis of $\mathrm{CD}$ are based on the centricity of the disease rather than on the histopathology. Surgical resection of UCDs can be curative, with long-term, recurrence-free survival described in the majority of case reports and series. The tumor's

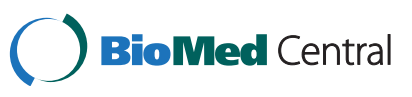


location and relationship with adjacent structures are important factors in predicting surgical morbidity $[2,14]$. MCD, however, often presents additional diagnostic uncertainty and treatment challenges. Immunotherapy, chemotherapy and antiviral therapy are the mainstays of treatment. Surgical treatment is reserved for either excisional biopsy, debulking of a dominant disease focus or palliative resection $[14,15]$. Transformation into nonHodgkin's lymphoma may occur, and, despite treatment, mortality due to MCD occurs in $40 \%$ of patients within 10 years from the time of diagnosis [14].

In the present report, we describe a rare case of retroperitoneal UCD and discuss a multidisciplinary approach to diagnosis and treatment of patients with this rare clinical entity.

\section{Case presentation}

A 61-year-old Caucasian woman was seen by her primary care physician for a palpable abdominal mass that had been present for $1 \frac{1 / 2}{2}$ years. She did not complain of systemic symptoms, general malaise, weight loss, flank pain or urinary symptoms, but described mild diarrhea and right periumbilical pain that radiated to the right lower quadrant. Her medical history included wellcontrolled hypertension and type 2 diabetes mellitus. Her previous colonoscopic and endoscopic evaluations were normal. During her physical examination, a nontender, immobile mass was palpable in the right lower quadrant without peripheral lymphadenopathy. Examination and laboratory studies were otherwise unremarkable. Computed tomography $(\mathrm{CT})$ with intravenous and oral contrast of the abdomen and pelvis revealed a heterogeneously enhancing, $10.2 \times 6.9 \times 6.3-\mathrm{cm}$ solid mass in the right retroperitoneal space immediately lateral to and displacing the inferior vena cava and right iliac vasculature (Figure 1A and 1B). Significant deformation of adjacent retroperitoneal structures was also observed. There was no evidence of abdominopelvic adenopathy or intraperitoneal disease. A biopsy was not performed.

An exploratory laparotomy revealed a large mass with remarkable tumor and perivascular inflammatory changes extending to the right iliac vessels and over the inferior vena cava. The mass was completely resected without the need for multiorgan resection. The blood loss during surgery was approximately $1 \mathrm{~L}$. The patient underwent a complete curative resection. She recovered well following the operation and was discharged on the seventh postoperative day. The patient has remained without radiologic evidence of disease recurrence during 2 years of follow-up.

\section{Pathological findings}

A soft encapsulated mass measuring $11.5 \times 6.0 \times 5.0 \mathrm{~cm}$ with tannish orange cut surfaces was identified in a surgical tissue specimen that had attached fatty and inflammatory soft tissue (Figure 2). All surgical margins were clear, with the closest approximately $2.0 \mathrm{~cm}$ from the lateral aspect of the inferior vena cava.

Under the microscope, we could see that the nodule consisted of lymphocytes with marked vascular proliferation and prominent hyalinization. Low- and high-power histopathology revealed regressively transformed germinal centers with normal B-cell distribution surrounded by hypervascular mantle zones composed predominantly of concentric rings ("onion-skinning") of small cluster of differentiation 4 (CD4)-positive $\mathrm{T}$ lymphocytes and plasma cells (Figures 3 and 4). We frequently observed hyalinized blood vessels perforating the follicles from the mantle zone. Immunostaining for CD21 demonstrated the characteristic follicular dendritic network of

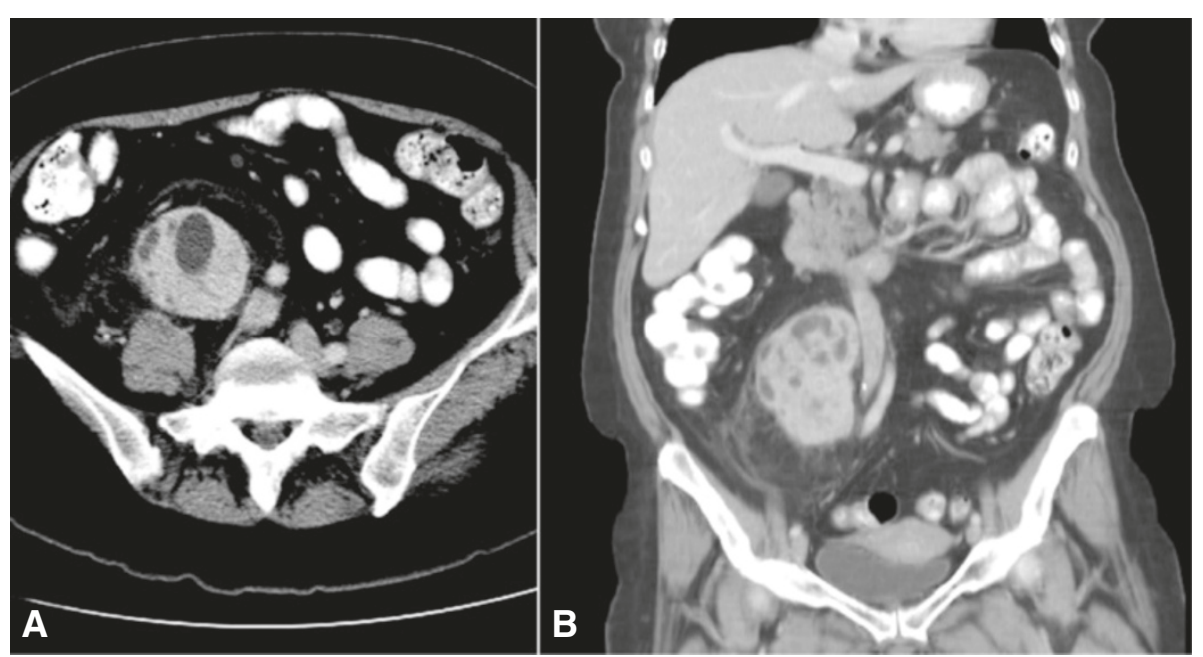

Figure 1 Preoperative imaging. (A) and (B) Axial and coronal computed tomographic scans, respectively, with oral and intravenous contrast showing a large, heterogeneously enhancing retroperitoneal mass deforming the inferior vena cava at the level of the right renal vein (arrow). 


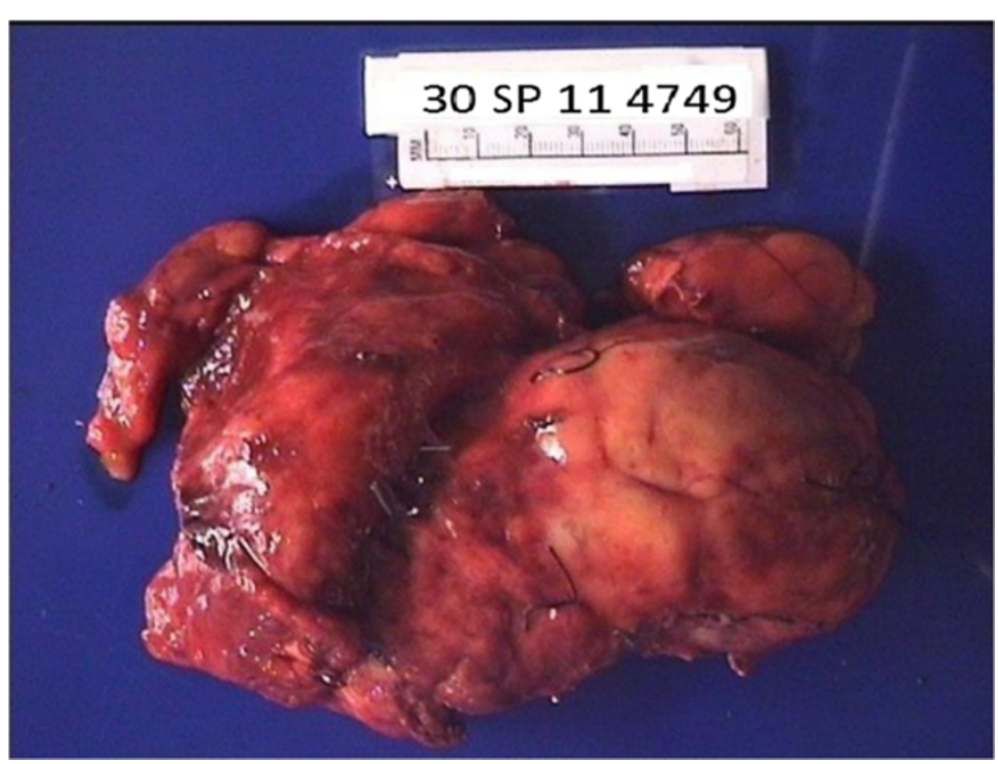

Figure 2 Gross specimen. The resected specimen surfaces weighed $340 \mathrm{~g}$ and measured $18 \times 11 \times 7 \mathrm{~cm}$. The tissue specimen contained an encapsulated mass that measured $11.5 \times 6.0 \times 5.0 \mathrm{~cm}$ and a medial border $2.0 \mathrm{~cm}$ from the border of the inferior vena cava.

residual germinal centers (Figure 5). CD10 was also weakly positive in some of the transformed germinal centers. PCR analysis of paraffin-embedded tissue targeting the $\mathrm{T}$-cell receptor $\gamma$ gene revealed no gene rearrangement. In situ hybridization for EBV and immunostaining for HHV-8 were both negative. These architectural features and immunochemical findings are consistent with HV-CD.

\section{Discussion}

Our patient presented to our institution with a rare, symptomatic, retroperitoneal, unicentric HV-CD tumor. Although etiologic factors continue to be elucidated [7], a major clinical challenge rests first on establishing the diagnosis of CD. An important initial step is a high clinical index of suspicion for CD in symptomatic patients [2]. Regardless of whether it presents as an incidental

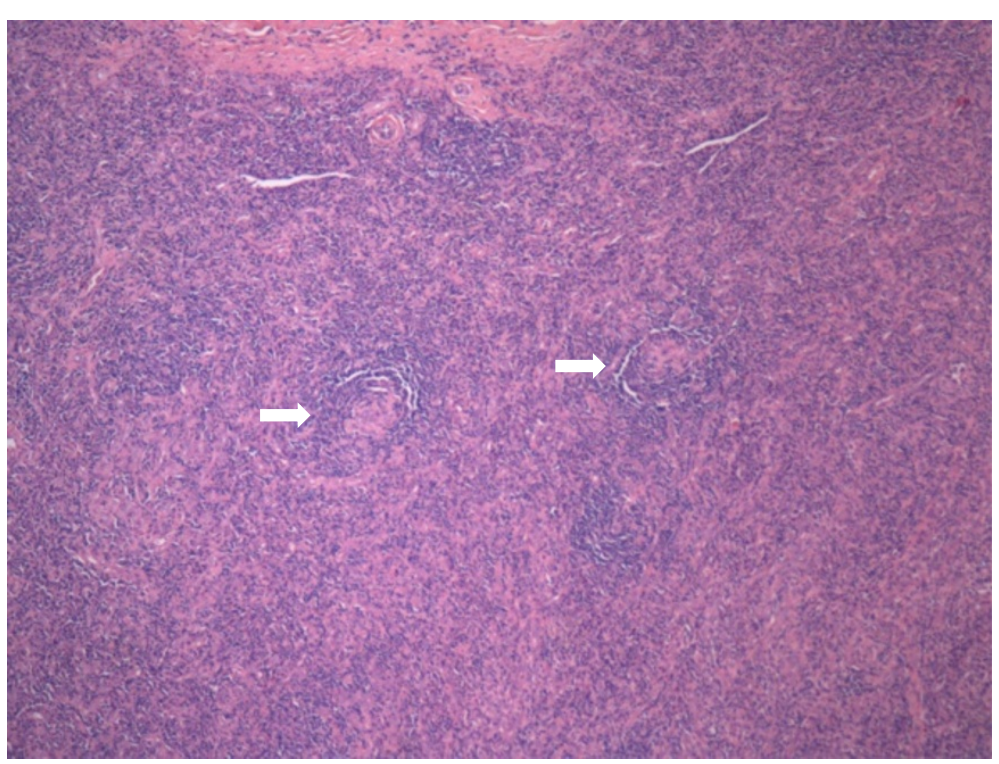

Figure 3 Histopathology. Microscopy of resected section showing two atrophic, hyalinized germinal centers (two-headed arrow) (hematoxylin and eosin stain; original magnification $4 \times$ ). 


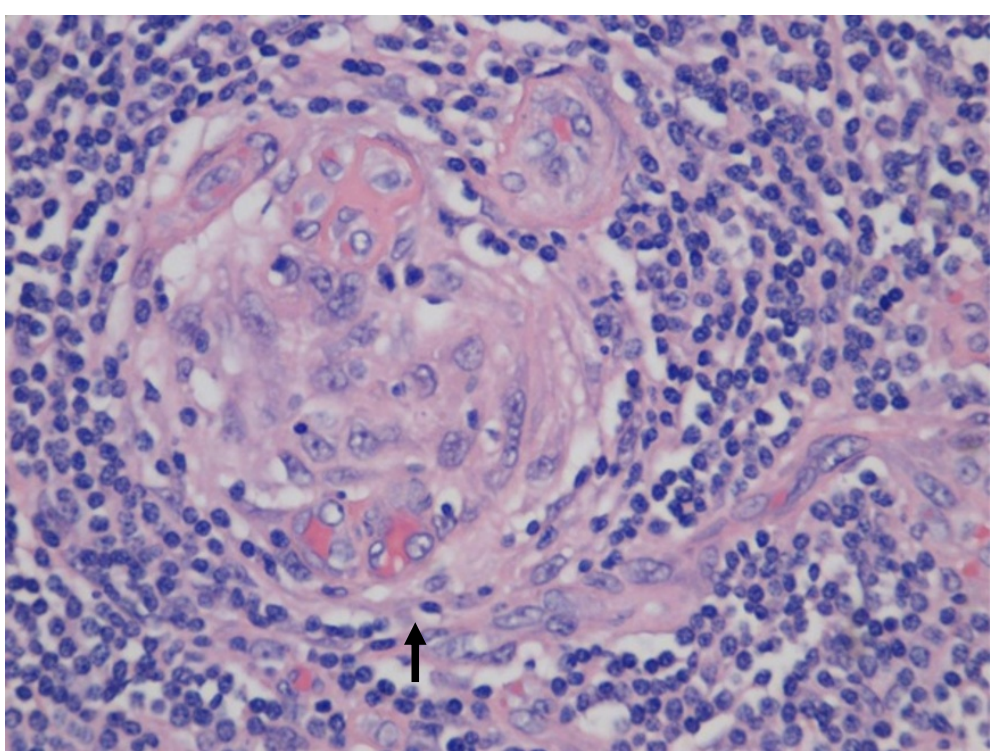

Figure 4 Histopathology. Microscopy of a section taken from the mass exhibiting the hyaline vascular features of Castleman's disease, including a characteristic endothelium-lined blood vessel radially penetrating an atrophic germinal center (arrow) (hematoxylin and eosin stain; original magnification, 20x)

finding or a symptomatic mass, CD is rarely included within differential diagnoses. Multidisciplinary review is highly recommended and may provide important insight into establishing the diagnosis of $\mathrm{CD}$.

Primary retroperitoneal tumors are particularly difficult to diagnose because of their location and often are clinically detected only after the tumor reaches a size that is large enough to be found with a resultant mass effect and involvement of surrounding structures. Among primary retroperitoneal tumors, one-third are sarcomas [16]. Liposarcomas comprise $70 \%$ of retroperitoneal sarcomas and can often be differentiated on cross-sectional imaging on the basis of fat distribution [17]. Lymphomas, carcinomas and neuroendocrine tumors, as well as extragonadal germ cell tumors, and metastatic melanomas, also occur in the retroperitoneum

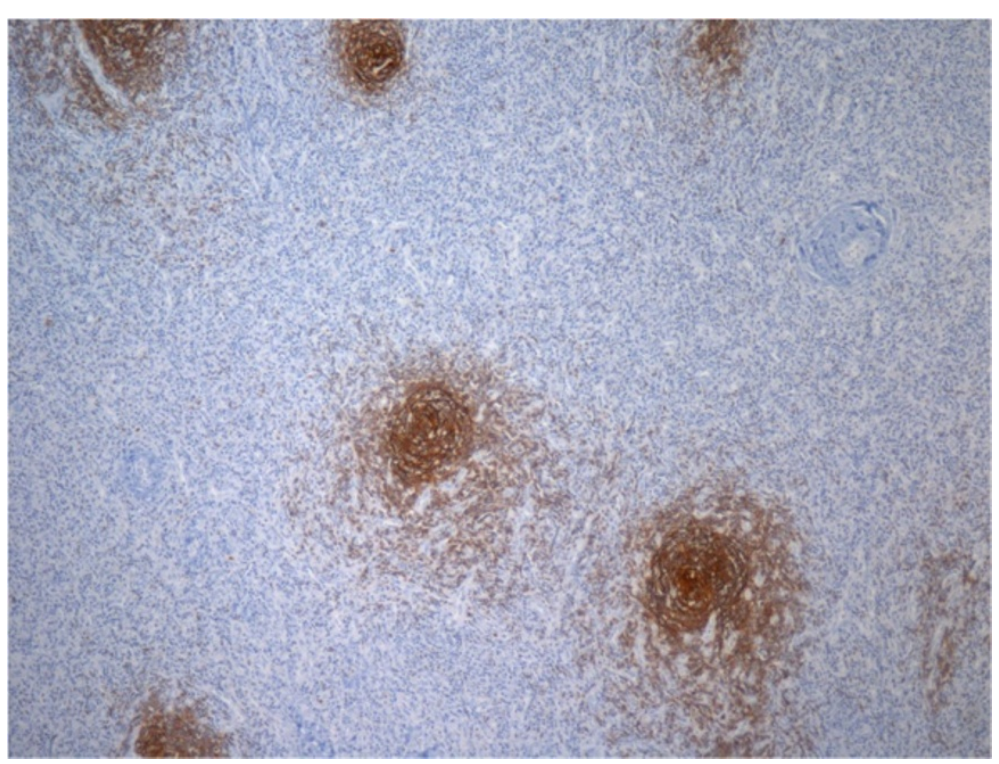

Figure $\mathbf{5}$ Histological image with immunostaining for cluster of differentiation $\mathbf{2 1}$ antibody. highlights the follicular dendritic network of residual germinal centers (arrow) (original magnification, 4X). 
The decision to biopsy retroperitoneal masses preoperatively remains controversial. At our institution, if a mass is suspected to be malignant and appears amenable to complete surgical resection, we frequently recommend surgical management without preoperative biopsy. Most surgeons agree that surgical resection in the appropriate clinical setting without biopsy is acceptable [18]. Biopsy is useful, however, in cases where radiology is inconclusive or tissue diagnosis prior to surgery may alter subsequent management [19]. Biopsy is also reasonable in patients whose performance status may preclude safe surgical resection, thus necessitating alternative therapies or treatment approaches. CT- or ultrasound-guided percutaneous biopsy is frequently used, and biopsy by endoscopic ultrasound has proven efficacious for retroperitoneal masses adjacent to the bowel [20]. Core-needle biopsy is often preferable to fine-needle aspiration to obtain appropriate specimens for pathologic evaluation, to differentiate variant histologic subtypes of mesenchymal tumors and to distinguish other types of tumors found within the retroperitoneum [21]. Furthermore, evaluation of rare clinical entities such as $\mathrm{CD}$ requires histologic architectural preservation provided by substantial tissue biopsies to render an accurate diagnosis.

An important clinical consideration in CD tumors is the degree of vascularity, which is more prominent in the HV-CD variant than in the PC-CD type. The degree of vascularity is relevant to both the diagnosis and treatment of CD. When CD presents in a rare location (for example, the head of the pancreas), the increased vascularity may confound the diagnosis and cause suspicion for primary malignancy with associated angiogenesis [22]. Zheng et al. [23] described characteristic findings of $\mathrm{CD}$ on $\mathrm{CT}$ scans, such as the degree of rim enhancement, that can assist in distinguishing CD from primary malignancy. Care must also be taken to differentiate UCD from MCD by using radiologic techniques, as treatment for these variants differs significantly. At our institution, we routinely employ dedicated $256 \times 256$ matrix multidetector CT cross-sectional imaging with arterial and venous phases for diagnostic and preoperative planning. Surgical resection of highly vascular tumors is technically challenging and is associated with morbidity and possible mortality related to blood loss. Recently published case reports have described the utilization of preoperative angiography and embolization to decrease intraoperative bleeding and subsequent morbidity [24-26].

Once the diagnosis or real clinical suspicion of UCD has been established, complete surgical resection is the treatment of choice on the basis of its reported longterm, recurrence-free survival rate with possible cure $[2,14]$. Importantly, surgical resection of large vascular tumors may be technically challenging, especially in the mediastinum and retroperitoneum, where vital structures tend to be involved with the tumor itself or with associated surrounding inflammatory and/or desmoplastic disease response. In many cases, resultant compression of vital structures due to mass effects necessitates the need to remove these lesions. Novel neoadjuvant approaches to facilitate safe surgical resection have been proposed. Bandera et al. [27] reported the successful use of rituximab (an anti-CD20 monoclonal antibody) in the neoadjuvant setting of mediastinal UCD involving the pulmonary artery and superior vena cava, followed by successful surgical resection. de Vries et al. [28] described the efficacious use of neoadjuvant radiotherapy for an unresectable abdominal UCD involving the iliac vessels to downsize the tumor, followed by complete surgical resection. In addition, a limited number of reports have addressed the response of CD to radiotherapy (2,700 to 4,500 cGy) administered to involved sites, with resultant remission of disease in isolated cases, suggesting a possible role for radiotherapy in a neoadjuvant or adjuvant setting [29-32]. Our present case report demonstrates the association of a CD-HV-type tumor with the inferior vena cava and in close proximity to the iliac vessels, which we treated with a technically challenging complete surgical resection. More investigation is required to further evaluate the utility of neoadjuvant strategies with the potential to reduce the size of tumors in cases where surgery may present a significant risk to the patient. In certain cases, if complete resection is not possible, partial resection or observation with long-term follow-up may be useful. Appropriate follow-up after surgical resection for the CD-HV type has not been established. We recommend routine CT yearly for the first 3 years and again at 5 years postoperatively. Thereafter follow-up imaging should be clinically driven based upon suspicion for disease recurrence.

Although the decision-making regarding of UCD and its management is challenging, MCD presents an even greater problem for the treating physician and surgeon. The use of antiviral and antiretroviral therapies is considered necessary with the addition of chemotherapeutic agents, including regimens developed for treatment of lymphoma and rituximab alone, which have demonstrated variable responses [15]. Despite aggressive medical management, the rates of relapse, malignant transformation and disease-related mortality remain high.

\section{Conclusion}

In this case report, we describe a rare case of retroperitoneal unicentric $\mathrm{HV}-\mathrm{CD}$, a poorly understood disease that creates a diagnostic and therapeutic dilemma for surgeons. To date, the use of improved radiologic criteria for diagnosis, interventional techniques and operative, neoadjuvant and adjuvant strategies appear to play an increasingly important role in the diagnosis and management of patients with this rare disease. Because of 
the rarity of $\mathrm{CD}$, the opportunity for clinical trials to produce uniform evidence-based approaches is unlikely. With regard to the treatment options for patients with these rare tumors, we encourage a collaborative, multidisciplinary approach that includes surgical specialists, radiologists, pathologists and oncologists to discuss treatment options to optimize patient outcomes.

\section{Consent}

Written informed consent was obtained from the patient for publication of this case report and any accompanying images. A copy of the written consent is available for review by the Editor-in-Chief of this journal.

\section{Competing interests}

The authors declare that they have no competing interests.

\section{Authors' contributions}

AW acquired data and drafted and revised the manuscript. AS and SH made the pathologic diagnosis and revised the manuscript. RR, MH, BB and MS were the pre- and postoperative treatment team and revised the manuscript. MW was responsible for surgical management and revised the manuscript. WB was the treating surgeon and drafted and revised the manuscript. All authors read and approved the final manuscript.

\section{Acknowledgements}

The authors gratefully acknowledge the assistance of our chairman of the Department of Surgery (D. Scott Lind MD) for his critical review of this manuscript. Furthermore, we are grateful to the members of the Department of Surgery for the care of this patient.

\section{Author details}

${ }^{1}$ Division of Surgical Oncology, Department of Surgery, Drexel University College of Medicine, 254 N. 15th St., MS 413, Philadelphia, PA 19102, USA ${ }^{2}$ Department of Pathology, Drexel University College of Medicine, $254 \mathrm{~N}$. 15th St., MS 435, Philadelphia, PA 19102, USA. Division of Hematology/ Oncology, Department of Internal Medicine, Drexel University College of Medicine, 245 N. 15th St., 8th Floor, Philadelphia, PA 19102, USA.

${ }^{4}$ Department of Diagnostic Radiology, Hahnemann University Hospital, 230 N. Broad St., MS 206, Philadelphia, PA 19102, USA. ${ }^{5}$ Division of Vascular Surgery, Department of Surgery, Drexel University College of Medicine, 254 N. 15th St., MS 413, Philadelphia, PA 19102, USA.

Received: 30 April 2013 Accepted: 2 January 2014

Published: 4 February 2014

\section{References}

1. Castleman B, Iverson L, Menendez VP: Localized mediastinal lymph node hyperplasia resembling thymoma. Cancer 1956, 9:822-830.

2. Bowne WB, Lewis JJ, Filippa DA, Niesvizky R, Brooks AD, Burt ME, Brennan MF: The management of unicentric and multicentric Castleman's disease: a report of 16 cases and a review of the literature. Cancer 1999, 85:706-717.

3. Bucher P, Chassot G, Zufferey G, Ris F, Huber O, Morel P: Surgical management of abdominal and retroperitoneal Castleman's disease. World J Surg Oncol 2005, 3:33.

4. Keller AR, Hochholzer L, Castleman B: Hyaline-vascular and plasma-cell types of giant lymph node hyperplasia of the mediastinum and othe locations. Cancer 1972, 29:670-683.

5. Bonekamp D, Horton KM, Hruban RH, Fishman EK: Castleman disease: the great mimic. Radiographics 2011, 31:1793-1807.

6. Jang SY, Kim BH, Kim JH, Ha SH, Hwang JA, Yeon JW, Kim KH, Paik SY: A case of Castleman's disease mimicking a hepatocellular carcinoma: a case report and review of literature. Korean J Gastroenterol 2012, 59:53-57.
7. Wang H, Wieczorek RL, Zenilman ME, Desoto-Lapaix F, Ghosh BC, Bowne WB: Castleman's disease in the head of the pancreas: report of a rare clinical entity and current perspective on diagnosis, treatment, and outcome. World J Surg Oncol 2007, 5:133.

8. Cronin DM, Warnke RA: Castleman disease: an update on classification and the spectrum of associated lesions. Adv Anat Pathol 2009, 16:236-246

9. Gaba AR, Stein RS, Sweet DL, Variakojis D: Multicentric giant lymph node hyperplasia. Am J Clin Pathol 1978, 69:86-90.

10. Menke DM, Camoriano JK, Banks PM: Angiofollicular lymph node hyperplasia: a comparison of unicentric, multicentric, hyaline vascular, and plasma cell types of disease by morphometric and clinical analysis. Mod Pathol 1992, 5:525-530.

11. Powles T, Stebbing J, Bazeos A, Hatzimichael E, Mandalia S, Nelson M, Gazzard B, Bower M: The role of immune suppression and HHV-8 in the increasing incidence of HIV-associated multicentric Castleman's disease. Ann Oncol 2009, 20:775-779.

12. Chen CH, Liu HC, Hung TT, Liu TP: Possible roles of Epstein-Barr virus in Castleman disease. J Cardiothorac Surg 2009, 4:31.

13. Muskardin TW, Peterson BA, Molitor JA: Castleman disease and associated autoimmune disease. Curr Opin Rheumatol 2012, 24:76-83.

14. Talat N, Belgaumkar AP, Schulte KM: Surgery in Castleman's disease: a systematic review of 404 published cases. Ann Surg 2012, 255:677-684

15. van Rhee F, Stone K, Szmania S, Barlogie B, Singh Z: Castleman disease in the 21 st century: an update on diagnosis, assessment, and therapy. Clin Adv Hematol Oncol 2010, 8:486-498.

16. Hueman MT, Herman JM, Ahuja N: Management of retroperitoneal sarcomas. Surg Clin North Am 2008, 88:583-597. vii.

17. Jemal A, Thomas A, Murray T, Thun M: Cancer statistics, 2002. CA Cancer J Clin 2002, 52:23-47. Published errata appear in CA Cancer J Clin 2002, 52:181-182, and CA Cancer J Clin 2002, 52:119

18. Windham TC, Pisters PW: Retroperitoneal sarcomas. Cancer Control 2005, $12: 36-43$.

19. Strauss DC, Hayes AJ, Thomas JM: Retroperitoneal tumours: review of management. Ann R Coll Surg Engl 2011, 93:275-280.

20. Kubota K, Kato S, Mawatari H, lida H, Akiyama T, Fujita K, Yoneda M, Takahashi H, Inamori M, Abe Y, Kirikoshi H, Kobayashi N, Saito S, Nakajima A: Risky endoscopic ultrasonography-guided fine-needle aspiration for asymptomatic retroperitoneal tumors. Dig Endosc 2010, 22:144-146.

21. Strauss DC, Qureshi YA, Hayes AJ, Thway K, Fisher C, Thomas JM: The role of core needle biopsy in the diagnosis of suspected soft tissue tumours. J Surg Oncol 2010, 102:523-529.

22. Inoue $\mathrm{Y}$, Nakamura H, Yamazaki K, Mizumoto S, Kokubu I, Mori H: Retroperitoneal Castleman's tumors of hyaline vascular type: imaging study case report. Clin Imaging 1992, 16:239-242.

23. Zheng X, Pan K, Cheng J, Dong L, Yang K, Wu E: Localized Castleman disease in retroperitoneum: newly discovered features by multi-detector helical CT. Abdom Imaging 2008, 33:489-492.

24. Robert JH, Sgourdos G, Kritikos N, Didier D, Terraz S: Preoperative embolization of hypervascular Castleman's disease of the mediastinum. Cardiovasc Intervent Radiol 2008, 31:186-188.

25. Sanchez-Ros-Sanchez A, Infante-Cossio P, Gonzalez-Garcia A, Borrero-Martin Jנ: Preoperative embolization for the treatment of cervical Castleman disease. J Craniofac Surg 2012, 23:e257-e259.

26. Swee W, Housseini AM, Angle JF, Jones DR, Daniel TM, Turba UC, AbdelGawad EA, Hagspiel KD: Preoperative embolization of Castleman's disease using microspheres. Ann Thorac Surg 2009, 88:1999-2001.

27. Bandera B, Ainsworth C, Shikle J, Rupard E, Roach M: Treatment of unicentric Castleman disease with neoadjuvant rituximab. Chest 2010, 138:1239-1241.

28. de Vries IA, van Acht MM, Demeyere T, Lybeert ML, de Zoete JP Nieuwenhuijzen GA: Neoadjuvant radiotherapy of primary irresectable unicentric Castleman's disease: a case report and review of the literature. Radiat Oncol 2010, 5:7.

29. Marti S, Pahissa A, Guardia J, Moragas A, Bacardi R: Multicentric giant follicular lymph node hyperplasia: favorable response to radiotherapy. Cancer 1983, 51:808-810.

30. Sethi T, Joshi K, Sharma SC, Gupta BD: Radiation therapy in the management of giant lymph node hyperplasia. Br J Radiol 1990, 63:648-650 
31. Veldhuis GJ, van der Leest AH, de Wolf JT, de Vries EG, Vellenga E: A case of localized Castleman's disease with systemic involvement: treatment and pathogenetic aspects. Ann Hematol 1996, 73:47-50.

32. Weisenburger DD, DeGowin RL, Gibson P, Armitage JO: Remission of giant lymph node hyperplasia with anemia after radiotherapy. Cancer 1979, 44:457-462.

doi:10.1186/1477-7819-12-30

Cite this article as: Williams et al: Retroperitoneal Castleman's disease: advocating a multidisciplinary approach for a rare clinical entity. World Journal of Surgical Oncology 2014 12:30.

\section{Submit your next manuscript to BioMed Central and take full advantage of:}

- Convenient online submission

- Thorough peer review

- No space constraints or color figure charges

- Immediate publication on acceptance

- Inclusion in PubMed, CAS, Scopus and Google Scholar

- Research which is freely available for redistribution 